\title{
Hypothalamic hamartomas. Part 1. Clinical, neuroimaging, and neurophysiological characteristics
}

\author{
Sandeep Mittal, M.D., F.R.C.S.C., ${ }^{1}$ Monika MitTal, M.D., ${ }^{1}$ José Luis Montes, M.D., ${ }^{2}$ \\ Jean-Pierre Farmer, M.D., F.R.C.S.C., ${ }^{2}$ and Frederick Andermann, M.D., F.R.C.P.C. ${ }^{3}$ \\ ${ }^{1}$ Department of Neurosurgery, Comprehensive Epilepsy Center, Wayne State University, Detroit Medical \\ Center, Detroit, Michigan; ${ }^{2}$ Department of Neurosurgery, Montreal Children's Hospital; and ${ }^{3}$ Department of \\ Neurology and Neurosurgery, Montreal Neurological Institute, McGill University, Montreal, Quebec, Canada
}

\begin{abstract}
Hypothalamic hamartomas are uncommon but well-recognized developmental malformations that are classically associated with gelastic seizures and other refractory seizure types. The clinical course is often progressive and, in addition to the catastrophic epileptic syndrome, patients commonly exhibit debilitating cognitive, behavioral, and psychiatric disturbances. Over the past decade, investigators have gained considerable knowledge into the pathobiological and neurophysiological properties of these rare lesions. In this review, the authors examine the causes and molecular biology of hypothalamic hamartomas as well as the principal clinical features, neuroimaging findings, and electrophysiological characteristics. The diverse surgical modalities and strategies used to manage these difficult lesions are outlined in the second article of this 2-part review. (http://thejns.org/doi/abs/10.3171/2013.3.FOCUS1355)
\end{abstract}
KEY WoRDS - gelastic seizure • epilepsy syndromes • precocious puberty • intrinsic epileptogenesis • sessile hamartoma • pedunculated hamartoma

$\mathrm{H}$ AMARTOMA, derived from the Greek word "hamartion" (denoting a bodily defect) is a focal benign growth in which cellular and other components normally found in the tissue mature in a disorganized manner. That is, hamartomas are the result of an aberrant development of normal tissue. However, the underlying causes of the abnormality remain incompletely understood. Although hamartomas resemble tumors in certain ways, they clearly do not have a tendency for neoplastic evolution. Instead, they grow at the same rate as the tissue from which they are derived.

Hypothalamic hamartomas are rare, heterotopic masses consisting of a disordered collection of mature neurons, glia, and fiber bundles. ${ }^{33}$ They arise from the floor of the third ventricle, tuber cinereum, or mammil-

\footnotetext{
Abbreviations used in this paper: Cho $=$ choline; $\mathrm{CPP}=$ central precocious puberty; $\mathrm{Cr}=$ creatine; $\mathrm{EEG}=$ electroencephalography; GABA $=\gamma$-aminobutyric acid $; \mathrm{GnRH}=$ gonadotropin-releasing hormone; $\mathrm{HH}=$ hypothalamic hamartoma; $\mathrm{mI}=$ myoinositol; $\mathrm{MEG}$ = magnetoencephalography; $\mathrm{MRS}=\mathrm{MR}$ spectroscopy; $\mathrm{NAA}=$ $N$-acetylaspartate; $\mathrm{PHS}=$ Pallister-Hall syndrome; $\mathrm{SHH}=$ sonic hedgehog.
}

lary bodies. These developmental malformations can be diagnosed incidentally during routine autopsy and even in utero. ${ }^{1,25,89}$ They frequently present with a variety of neurological and endocrine disturbances. In its most debilitating form, a progressive epileptic encephalopathy appears during early childhood. The true prevalence of epilepsy due to $\mathrm{HH}$ remains unknown, but is estimated to be $1-2$ per $100,000 .{ }^{116}$ In addition to gelastic seizures, a hallmark of HH-related epilepsy, the syndrome is also commonly characterized by other types of intractable seizures. Also, patients with $\mathrm{HH}$ often display severe $\operatorname{cog}$ nitive impairment, pervasive developmental disorders, psychiatric disorders, and other major behavioral disturbances. Central precocious puberty occurs in a distinct subtype of patients with $\mathrm{HH}$.

\section{Topographic and Functional Anatomy}

The hypothalamus is the most integrative structure in the cerebrum. Located around the base of the cerebrum, the hypothalamus surrounds the third ventricle and extends from the optic chiasm anteriorly to the mammillary bodies posteriorly. It weighs less than $2.5 \mathrm{~g}$ in the 
adult human. ${ }^{36}$ In midsagittal section, the boundaries of the hypothalamus are defined by the hypothalamic sulcus superiorly, by the lamina terminalis anteriorly, by a line between the caudal aspect of the mammillary body and the posterior commissure posteriorly, and ventrally by the tuber cinereum, a gray matter protuberance along the floor of the third ventricle. ${ }^{44}$ The lateral border of the hypothalamus is less well defined and is roughly limited by the optic tract, internal capsule, cerebral peduncle, and subthalamus. Longitudinally, 2 zones define the hypothalamus: a densely cellular medial zone and a relatively paucicellular lateral zone separated by a sagittal plane passing through the anterior columns of the fornix. ${ }^{36}$ The majority of named hypothalamic nuclei in humans are located in the medial zone.

The hypothalamus coordinates various autonomic, somatic, endocrine, and behavioral activities through its abundant reciprocal afferent and efferent connections. It receives input from and in turn projects to various neuronal populations of the forebrain, brainstem, and spinal cord. Remarkably, the hypothalamus is also associated with laughter, the behavioral manifestation of mirth, ${ }^{8,44}$ as well as other emotional conditions such as sadness. ${ }^{99}$

\section{Etiological and Molecular Biological Characteristics}

The embryological origin and underlying cause of $\mathrm{HHs}$ remain largely unknown. The true incidence of $\mathrm{HH}$ is uncertain, but the prevalence of epilepsy associated with HHs was approximately 0.5 per 100,000 in one Swedish study. ${ }^{17}$ Hypothalamic hamartomas are usually sporadic, and their precise cause has yet to be determined. However, rather than presenting as isolated masses, HHs can sometimes be part of a multiple congenital malformation syndrome. In fact, $\mathrm{HHs}$ have been described in a number of congenital anomaly syndromes. These syndromic HHs generally have a milder phenotype than their nonsyndromic, sporadic counterparts; however, both forms probably arise from similar pathogenetic mechanisms. The identification of genes associated with HHs can also help us better understand how these genes are involved in the normal development and function of the hypothalamus.

First described in 1980 in 6 children, PHS is one of the most thoroughly studied developmental disorders in terms of its molecular pathology. ${ }^{50}$ The condition is classically characterized by the presence of an $\mathrm{HH}$ in association with a spectrum of multiorgan malformations including central postaxial polydactyly, pituitary hypoplasia, bifid epiglottis, dysplastic nails, and imperforate anus. In some patients cardiac and renal anomalies as well as mild mental retardation are also present. Given this characteristic phenotype, PHS is commonly diagnosed at birth. With an autosomal dominant pattern of inheritance and variable penetrance, familial cases of PHS have been linked to a mutation in a zinc finger transcription factor gene, GLI3, on chromosome $7 \mathrm{p} 13$ in certain inherited probands. ${ }^{60}$ The GLI proteins act downstream of the SHH signaling pathway and regulate target gene expression ${ }^{88}-\mathrm{SHH}$ has a critical role in directing dorsoventral patterning of the developing CNS. ${ }^{15}$ The GLI3 transcription factor, in the presence of $\mathrm{SHH}$, is released intact and migrates into the nucleus and activates downstream genes. When SHH is absent, GLI3 is cleaved by a protease into a shorter isoform that enters the nucleus and acts as a transcriptional repressor of target genes. In children with PHS, frameshift mutations in the GLI3 gene result in the formation of a truncated protein, which is functionally identical to the shorter, processed, repressor form of the protein. ${ }^{68}$ Therefore, the pathogenetic mutations in patients with PHS eliminate the capacity of SHH to switch GLI3 between the repressor and activator state.

Moreover, recent studies suggest that somatic GLI3 mutations can also lead to spontaneous nonsyndromic $\mathrm{HH}$ and gelastic seizures. ${ }^{34,115}$ Investigators at the Barrow Neurological Institute previously reported on a patient with a sporadic $\mathrm{HH}$ not associated with PHS; the HH had a segmental anomaly on chromosome $6 \mathrm{p} .{ }^{61}$ The patient, a full-term infant with microcephaly and other subtle dysmorphic features, was found to harbor a duplication of the distal short arm of chromosome 6. The authors identified 6p25.1-25.3 as a potential susceptibility locus for sporadic $\mathrm{HHs}$ and postulated that, among the genes in the involved telomeric region, FOXCl is the candidate gene most likely to be implicated in HH pathogenesis. ${ }^{61}$ The FOXC1 gene, like GLI3, expresses a DNA-binding transcription factor.

Certainly, substantial work is required to establish the precise role that $G L I 3, F O X C 1$, and other putative genes play in the genesis of HHs. ${ }^{85}$

\section{Clinical Characteristics}

There is a strong relationship between the clinical features associated with HHs and their physical connection to normal hypothalamic and surrounding tissues. In addition to the characteristic gelastic seizures, patients with $\mathrm{HH}$ also frequently have various other seizure types that tend to evolve over time. In addition to the epileptic syndromes, $\mathrm{HHs}$ are often associated with precocious puberty, behavioral disorders, and progressive cognitive decline. Neurosurgical intervention can often lead to dramatic improvements of the severe epileptic, behavioral, psychiatric, and neurocognitive disturbances seen in these patients.

\section{Epileptic Syndromes}

Trousseau first described the phenomenon of "pressure to laugh" or gelastic epilepsy in $1873 .{ }^{108}$ The term "gelastic epilepsy," the hallmark of HHs, was coined by Daly and Mulder in 1957. ${ }^{35}$ Derived from the Greek word gelos meaning mirth, gelastic seizures typically arise in early childhood, often in the neonatal period, and are invariably followed by development of a medically intractable catastrophic seizure disorder. Gelastic attacks, first defined by Gascon and Lombroso in 1971, ${ }^{47}$ are characterized by repeated short-lasting seizures with initial emotionless laughter or grimacing. Some patients have vocalization during the ictus similar to crying instead of laughing, in addition to grimacing. These types 


\section{Clinical, neuroimaging, and neurophysiological features of $\mathrm{HHs}$}

of seizures are termed "dacrystic seizures."19 Features of dacrystic and gelastic seizures may occur in the same individual and even during the same seizure. These seizure types are often difficult to diagnose at birth because they may be easily misinterpreted as normal laughter or colic. ${ }^{51}$ In addition to ictal laughter, other seizure types commonly develop later in the course of the disease, which are often more disabling than the gelastic spells. ${ }^{24,78} \mathrm{Nev}$ ertheless, the vast majority of electrophysiological studies have focused on gelastic seizures.

The presence of multiple seizure types in patients with $\mathrm{HH}$, including generalized tonic-clonic seizures, complex partial seizures, drop attacks, and atypical absences have been reported..$^{10,23,24,43,70}$ Tassinari and colleagues ${ }^{106}$ published an extensive review of patients with gelastic seizures in which they reported on 60 patients with gelastic seizures without the presence of $\mathrm{HH}$, suggesting that ictal laughter is not necessarily pathognomonic for $\mathrm{HH}$. In fact, gelastic seizures may also be present in frontal and temporal lobe epilepsies. ${ }^{26,51,53,66,80,109}$ Ictal laughter has also been described in patients with focal cortical dysplasia, tuberous sclerosis, pituitary tumors, gliomas, meningiomas, and rarely in basilar artery aneurysms..$^{30,32,98}$ Tassinari et al. then detailed the profile of another 60 patients with gelastic seizures in association with $\mathrm{HH}$. In 51 of these 60 patients with $\mathrm{HH}$, gelastic seizures were the first observed seizure type. However, more than $75 \%$ of patients had other types of intractable seizures, including complex partial seizures with or without secondary generalization in $35.5 \%$, "falling" seizures in $33.3 \%$, tonic seizures in $17.7 \%$, and tonic-clonic seizures in $15.1 \%$. Harvey and Freeman ${ }^{51}$ reported that generalized seizures can occur in up to $70 \%$ of severely affected patients undergoing surgery. Later onset of epilepsy may be associated with a milder epileptic syndrome with less prominence of gelastic seizures. In addition, cognitive and behavioral problems may be less prevalent in adults compared with children harboring an $\mathrm{HH}^{77}$

It is rare for complex partial seizures to be the presenting seizure type in $\mathrm{HH}$. In fact, when complex partial seizures are thought to be the presenting type, it is quite likely that patients had experienced previously undiagnosed gelastic seizures. Features of complex partial seizures associated with $\mathrm{HH}$ include epigastric discomfort, fear, simple automatisms, axial movements, asymmetrical tonic posturing, and limb jerking. ${ }^{51}$ Oehl et al. ${ }^{81}$ examined the seizure semiology in 31 patients with $\mathrm{HH}$ and gelastic seizures. They concluded that, unlike in adults and adolescents, gelastic seizures were the dominant component of the semiology in children and that their seizures were significantly shorter in duration.

\section{Behavioral and Cognitive Disorders}

Patients with $\mathrm{HH}$ and pharmacoresistant gelastic seizures almost always develop a catastrophic epilepsy of childhood and severe epileptic encephalopathy. ${ }^{101}$ Frequent$\mathrm{ly}$, this epileptic syndrome is accompanied by profound behavioral difficulties, with hyperactivity, rage, and aggression being the most common. ${ }^{7,91,111,114}$ Occasionally, HH-associated ictal aggressive behavior can be misdiagnosed as a primary psychiatric disorder. ${ }^{2}$ In addition to delinquency and aggressive outbursts, a slowly progressive decline in cognitive functioning has also been frequently observed in patients with HH-related gelastic seizures. ${ }^{6,10,14,43,78}$ The decline of behavior and cognitive function typically parallels the exacerbation of the seizure disorder. Quiske et al. ${ }^{91}$ published the first in-depth report on cognitive performance in adult and juvenile patients with gelastic seizures and $\mathrm{HH}$, in which they found cognitive impairments in more than half of their patients. Similarly, Prigatano et al..$^{90}$ noted impaired intellectual test performance in patients with $\mathrm{HH}$ and refractory epilepsy.

Park et al. ${ }^{86}$ performed a limited study on quality of life in children with $\mathrm{HH}$. These authors used 2 agematched control groups who had either migraine headaches or benign epilepsy with centrotemporal spikes. Using a standardized measurement of pediatric quality of life, they found decreased quality of life in the $\mathrm{HH}$ group compared with the migraine group in all domains measured. The investigators also noted a significant decrease in quality of life in the $\mathrm{HH}$ group compared with the benign epilepsy group in the domain of school function.

\section{Psychiatric Disorders}

In addition to cognitive and behavioral disturbances, there is also a high prevalence of psychiatric comorbidity in patients with $\mathrm{HH} .{ }^{95}$ Weissenberger et al. ${ }^{116}$ evaluated 12 children between 3 and 14 years of age, along with the parents and age-matched siblings. They noted that children with $\mathrm{HH}$ and gelastic seizures had a significantly higher incidence of psychiatric comorbidities, such as oppositional defiant disorder $(83.3 \%)$, attention deficit-hyperactivity disorder (75\%), conduct disorder (33.3\%), and affective disorders (16.7\%). In their analysis of 10 adults with $\mathrm{HH}$ and intractable seizures, Ali et al. ${ }^{4}$ also noted a high prevalence of comorbid psychiatric disorders such as major depressive disorder and social anxiety disorder.

\section{Central Precocious Puberty}

There is a well-established link between $\mathrm{HH}$ and $\mathrm{CPP}$, which is defined as the onset of puberty before the age of 8 years in girls and 9 years in boys. ${ }^{12}$ Patients with pedunculated HHs (that is, those located below the third ventricle) rarely present with seizures. Rather, these lesions are commonly associated with CPP. The CPP related to $\mathrm{HH}$ tends to occur considerably earlier than idiopathic CPP. ${ }^{22}$ In fact, the first sign of CPP in patients with pedunculated hamartomas occurs before the age of 2 years in more than $80 \%$ of cases. Numerous hypotheses have been put forth in an attempt to explain the possible mechanisms by which HHs lead to precocious puberty. ${ }^{56}$ One hypothesis advocates the notion that HHs produce bioactive substances that mimic the series of events underlying the normal onset of puberty, thereby leading to an accelerated time course of sexual development. Others have suggested that because critical transcriptional and signaling networks necessary to initiate and sustain a pubertal pattern of $\mathrm{GnRH}$ release are present in $\mathrm{HH}$, these networks are capable of initiating puberty at an earlier age. Last, it is feasible that sporadic alterations in the same genes and morphogenic pathways that regulate 
embryonic maturation of the ventral hypothalamus and the floor of the third ventricle are also responsible for the formation of HHs.

Chan and coworkers ${ }^{27}$ examined 18 patients who underwent $\mathrm{HH}$ resection for intractable seizures, 7 of whom had CPP. The authors noted that HHs causing CPP were larger than those not associated with $\mathrm{CPP}$ and were more likely to maintain contact with the tuber cinereum or infundibulum. All 18 hamartomas expressed GnRH and transforming growth factor $\alpha$, which stimulated the release of GnRH. Expression of other candidate genes was not different between the 2 groups. ${ }^{27}$ Clearly, the precise mechanisms involved in $\mathrm{HH}$ causing CPP remain to be fully elucidated. ${ }^{85}$

\section{Neuroimaging Findings}

\section{Computed Tomography}

A small nonenhancing mass in the interpeduncular and suprasellar cistern isodense to normal brain parenchyma is typically seen on CT scans. ${ }^{52}$ There is often obliteration of the suprasellar cistern and anterior third ventricle. ${ }^{76}$ Metrizamide CT cisternography shows a filling defect in the suprasellar cistern and may greatly improve the diagnostic yield for smaller occult lesions of the hypothalamic-hypophyseal axis by clearly defining the size of the mass as well as its relationship to surrounding neurovascular structures. ${ }^{84}$ Rarely, HHs may become quite large and have calcifications and cystic components. ${ }^{39,119}$

\section{Magnetic Resonance Imaging}

High-resolution MRI scans have dramatically improved the diagnosis and surgical management of HHs and largely replaced all other diagnostic imaging modalities for evaluation of patients with lesions of the tuber cinereum. Freeman et al. ${ }^{45}$ methodically examined the MRI findings in 72 patients with $\mathrm{HH}$ and refractory epilepsy. They noted that most HHs (93\%) were hyperintense relative to cortical and deep gray matter on T2weighted images (Fig. 1). Contrary to prior studies, which reported that $\mathrm{HHs}$ were isointense with gray matter on T1-weighted images, ${ }^{13,49,72}$ Freeman et al. found that in 53 cases $(74 \%)$ these lesions were hypointense compared with normal gray matter. These authors thought that this might be due to higher signal intensity contrast among gray matter, white matter, and abnormal tissue acquired with inversion-prepared gradient-echo sequences, compared with conventional spin-echo sequences. Because they do not disrupt the blood-brain barrier, HHs do not enhance following administration of contrast.

\section{Magnetic Resonance Spectroscopy}

Magnetic resonance spectroscopy is highly sensitive in detecting neuronal dysfunction in patients with temporal lobe epilepsy. However, few studies have reported the spectroscopic properties of HHs. Nine published reports with a total of 44 patients have described the MRS findings evaluating the NAA, $\mathrm{Cr}$, Cho, and $\mathrm{mI}$ content within the hamartoma. The group in Montreal was the first to study the extent of neuronal injury in the temporal lobes and hamartomas of 5 patients with HHs and gelastic seizures by using proton MRS. ${ }^{105}$ The NAA/Cr ratio was significantly decreased in the patients with hamartomas compared with the hypothalami of healthy individuals. Likewise, Pascual-Castroviejo et al. ${ }^{87}$ used MRS to study the temporal lobes and the $\mathrm{HH}$ in 1 patient. The relative intensities of the NAA/Cr and the NAA/Cho ratios were not significantly different from those found in the temporal lobes of healthy volunteers. Within the $\mathrm{HH}$, the NAA/Cho ratio was decreased; however, contrary to the findings of Tasch et al., ${ }^{105}$ the NAA/Cr ratio was greatly increased in the aforementioned patient. ${ }^{87}$ Other small studies have reported similar findings. ${ }^{29,74,96,112}$

Two recent larger series shed further light on the MRS findings in HHs. First, Freeman et al. ${ }^{45}$ used proton MRS to evaluate 19 patients with $\mathrm{HH}$ and compared their results with the metabolite profile of the thalamus in 10 healthy children and of the frontal lobe in 10 healthy adults. Confirming previous reports, the authors found a reduction in NAA and an increase in $\mathrm{mI}$ content within the hamartoma. Likewise, Amstutz and coworkers ${ }^{5}$ analyzed data from single-voxel MRS in 14 patients with $\mathrm{HH}$. These authors noted a significant decrease in NAA/ $\mathrm{Cr}$ and an increase in $\mathrm{mI} / \mathrm{Cr}$ ratios in the $\mathrm{HH}$ compared with normal gray matter and amygdala. Moreover, Cho/ $\mathrm{Cr}$ ratios were also elevated when compared with those in gray matter of healthy volunteers.

Taken together, the MRS findings suggest that HHs have decreased neuronal density and relative gliosis compared with normal gray matter (Fig. 2).

\section{Intrinsic Epileptogenesis}

The classic relationship between HHs and epilepsy is often obscured by the slow spike and wave epileptiform patterns commonly seen in the frontal and/or temporal lobes. ${ }^{13}$ Interictal and ictal EEG are either normal or nonspecifically abnormal in patients with only gelastic seizures, often making diagnosis difficult. With onset of generalized seizures, there is an increase in interictal spike-wave activity with enhanced bilateral wave synchrony. ${ }^{51}$ Moreover, certain seizures in patients with HHs can resemble complex partial seizures originating from the frontal or temporal lobe both clinically and by scalp EEG. Troester et al. ${ }^{107}$ reviewed 102 EEGs obtained in 73 patients and found high variability in the interictal EEG, including normal readings. Findings encompassed focal, multifocal, and generalized spikes and waves. They reported that there were no obvious findings on ictal EEGs in patients with gelastic seizures. In some cases, despite ictal EEG monitoring with intracranial electrodes (not including depth electrodes within the $\mathrm{HH}$ itself), seizures can appear to arise from the frontal or temporal cortex. ${ }^{21}$ Nevertheless, neocortical resection has proven to be largely ineffective in abolishing $\mathrm{HH}-$ related gelastic attacks.

\section{Depth Electrode Recording}

Scalp EEG frequently fails to show the origin of 
Clinical, neuroimaging, and neurophysiological features of HHs
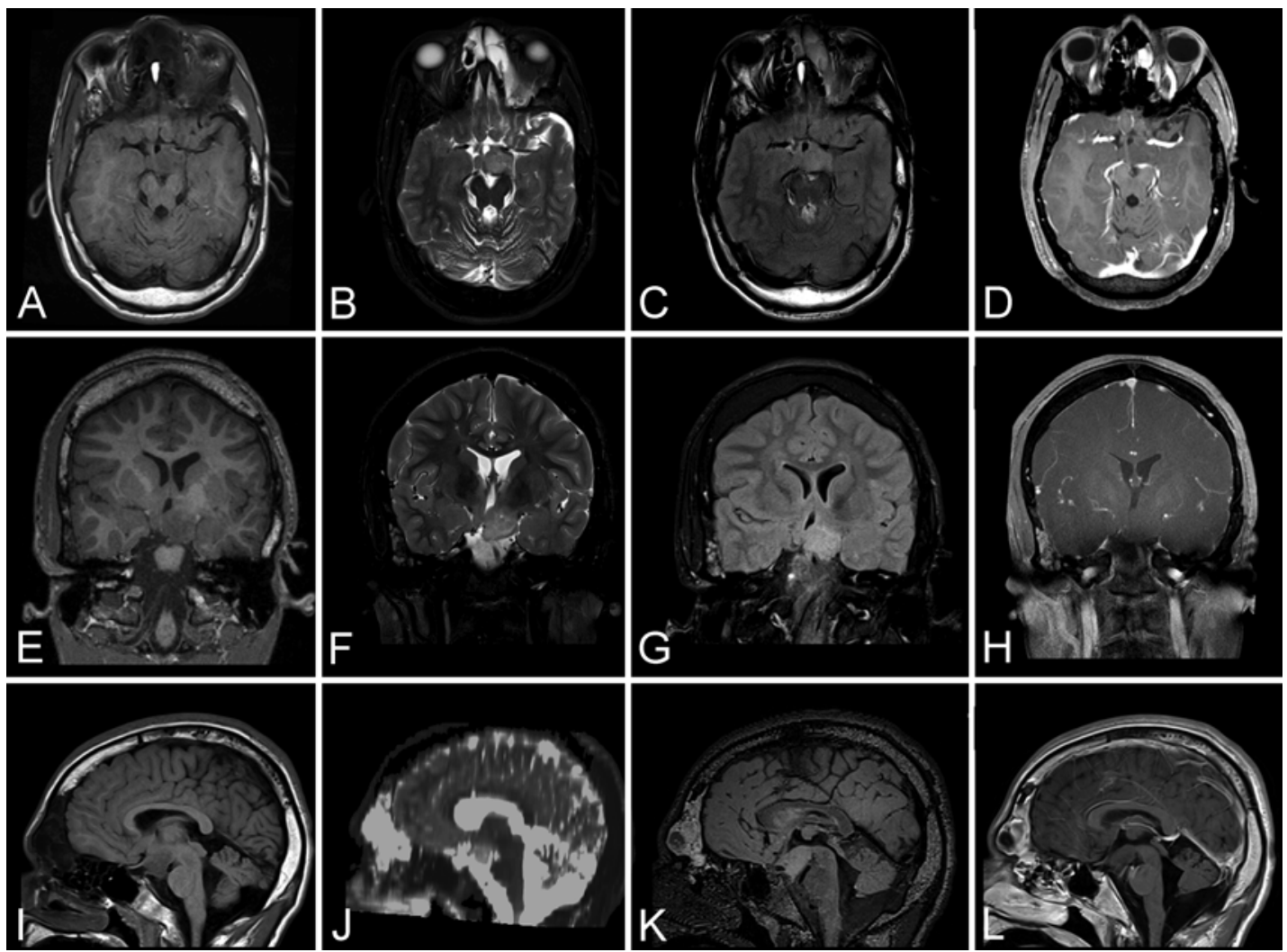

FIG. 1. Features of HHs on MRI. Brain MRI sequence obtained in a 19-year-old man with a long-standing history of gelastic seizures and neurocognitive disturbance. Axial images (A-D) show a large mass in the suprasellar cistern. The lesion is hypointense on T1-weighted images (A, E, I), slightly hyperintense on T2-weighted (B, F, J) and FLAIR (C, G, K) images, and does not enhance following administration of contrast agent $(D, H, L)$. The intraventricular component of the nonenhancing lesion shows lateral attachment to the hypothalamus.

gelastic seizures. ${ }^{55}$ This is in keeping with seizure onset in deep-seated structures where epileptic activity may not be captured by scalp electrodes. Munari's group in Grenoble obtained the first depth electrode recording directly from the $\mathrm{HH}$ in a patient with gelastic seizures. During the same period, the group in Montreal inserted depth electrodes within the $\mathrm{HH}$ in 2 children for long-term video-EEG monitoring (Fig. 3). These landmark studies provided, for the first time, direct evidence that the gelastic seizures originated from the hamartoma itself.79,82 Over the last 15 years, depth electrode studies from a small number of additional patients with $\mathrm{HH}$ have confirmed that ictal events manifested by gelastic seizures clearly arise from the $\mathrm{HH}$ itself. ${ }^{31,58,67}$ Interestingly, habitual seizures can be reproduced by electrical stimulation of the depth electrode contacts within the $\mathrm{HH}$ in some of these patients. ${ }^{31,58,67,79}$ Strong evidence for the intrinsic epileptogenesis of the $\mathrm{HH}$ was further strengthened by metabolic neuroimaging studies.

Complex partial seizures and generalized seizures may be indicative of the spread of discharges from the $\mathrm{HH}$ to frontal and temporal regions. These seizures are not associated with discharges from the HH itself, unlike the situation with gelastic seizures as described above.

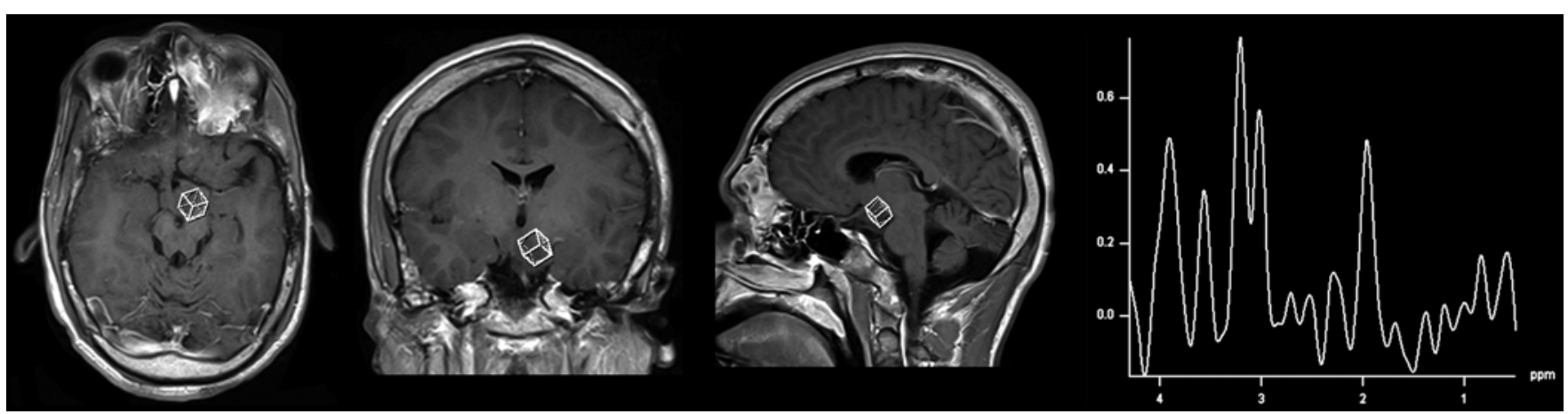

FIG. 2. Illustrative MRS studies. Within the hamartoma, the NAA peak is typically decreased and Cho is increased. The NAA/ Cho ratio is decreased whereas the $\mathrm{Cho/Cr}$ ratio is usually increased. This spectral pattern is indicative of diminished neuronal density. 

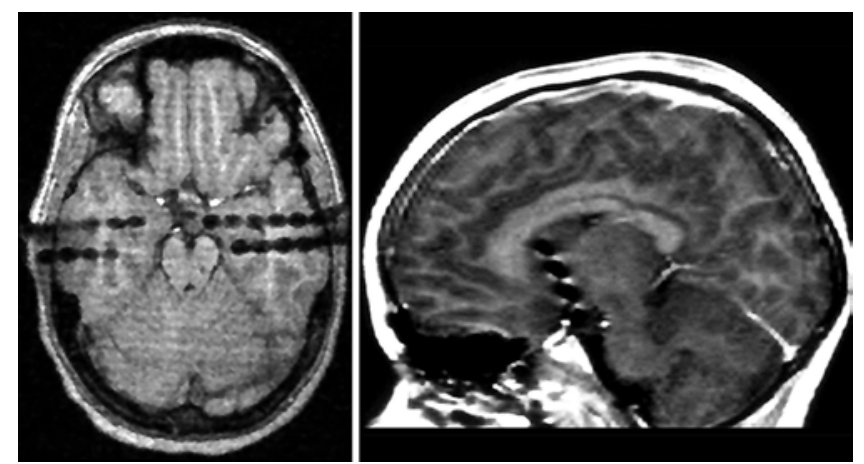

FIG. 3. Intrinsic epileptogenesis of $\mathrm{HH}$ confirmed with depth electrodes. A 7-year-old boy with intractable gelastic seizures and aggressive behavior underwent stereotactic implantation of depth electrodes into the $\mathrm{HH}$ (right) as well as bilateral mesial temporal lobes (left). Extraoperative ictal EEG monitoring revealed rhythmic activity originating from the hypothalamic contacts followed by fast activity spreading into both temporal lobes.

Lateralization of motor features of seizures and lateralization of interictal EEG often correspond to the side of attachment of the hamartoma in unilateral lesions. ${ }^{51}$

\section{Positron Emission Tomography}

Two studies have shown evidence of focal cortical hypometabolism colocalizing with the most prominent scalp EEG abnormalities on interictal FDG PET scans. ${ }^{82,94}$ Focal hypometabolism is generally seen in regions involved in the hamartoma-driven epileptic network. Whether these cortical anomalies result from propagation of ictal discharges or represent a potentially independent seizure onset zone remains unclear. Three studies have shown glucose hypermetabolism of the HH during epileptic activity. ${ }^{83,97,113}$ These elusive ictal FDG-PET studies independently confirmed that gelastic seizures in individuals with HHs do indeed originate in the hypothalamic mass.

\section{Single-Photon Emission Computed Tomography}

Additional evidence pinpointing the $\mathrm{HH}$ as the focus of seizure generation has been provided by quantification of regional cerebral blood flow during gelastic seizures. Several investigators obtained ictal SPECT scans by using either $\left[{ }^{99 m}\right]$ technetium hexamethylpropyleneamine oxime (Tc-HMPAO) or ${ }^{[99 \mathrm{~m}]}$ technetium ethyl cysteinate dimer (Tc-ECD) tracer. $918,37,38,40,42,59,67$ These reports have consistently verified that significant hyperperfusion is seen within the hamartoma after a gelastic seizure, with normalization during the interictal phase. These ictal SPECT studies lend further support to the concept that certain HHs are intrinsically epileptogenic.

Whether the inherent epileptogenicity of $\mathrm{HHs}$ can account for the entire clinical spectrum of epileptic, neuropsychological, behavioral, and psychiatric disorders associated with $\mathrm{HH}$ is far from certain. In fact, morphologically similar HHs can be associated with drastically different seizure and behavioral phenotypes.

\section{Functional MRI}

In a very elegant paper, Leal and colleagues ${ }^{69}$ performed simultaneous EEG and fMRI recording in a 2-year-old boy with medically refractory gelastic seizures related to an HH. Interictal EEG showed multifocal spikes predominantly over the frontal and occipital-temporal regions in the left hemisphere. These electrographic findings are in keeping with previous reports and correlate with the anatomical connections of the hypothalamus. ${ }^{70,78}$ The authors noted a strong and early blood oxygen level-dependent activation of the $\mathrm{HH}$ in 3 of the 5 seizures recorded in a single session. Interestingly, after onset in the hamartoma, the blood oxygen level-dependent response involved the left hippocampus and occipital lobe, and later the left cingulate gyrus and dorsal-lateral frontal lobe. ${ }^{69}$ Ictal EEG showed an early cortical activation of the left occipital-temporal area and later spread to the left frontal lobe. Such EEG-fMRI recordings may help to further characterize the dynamic model of seizure propagation pathways in patients with HHs.

There has been debate over whether multiple seizure types have an independent epileptogenic focus in areas that may be influenced by the activity of the hamartoma or if they are secondarily generated from spread of the epileptic discharges from the $\mathrm{HH}$ to the cerebral cortex. Kokkinos et al. ${ }^{65}$ performed EEG-fMRI studies in 2 patients with HHs and differing seizure presentations (one patient had predominantly gelastic seizures and the other had complex partial seizures without typical gelastic features) to determine any differences in the epileptogenic pathways. On interictal and ictal EEG-fMRI, they found that in the patient with gelastic seizures many areas outside the $\mathrm{HH}$ were involved in seizure onset, including the thalamus, cingulate gyrus, precuneus, and the frontal lobe. However, in the patient with complex partial seizures, the authors noted increased blood oxygen level-dependent signal in temporal lobes bilaterally as well as the basal frontal, precuneus, and anterior cingulate areas in the interictal analysis. Interestingly, the $\mathrm{HH}$ itself did not seem to be primarily involved in the seizure network. Although the study did reveal commonalities in the epileptogenic pathways for both types of seizures in this limited study, the authors concluded that a case could be made for either an independent epileptogenic focus secondary to the $\mathrm{HH}$ or secondary seizure generation from the $\mathrm{HH}$ itself. ${ }^{65}$

\section{Magnetoencephalography}

As a noninvasive tool, MEG provides cerebral magnetic activity data with excellent spatiotemporal resolution that is often complementary to EEG. ${ }^{46,101}$ In their preliminary study, Goldenholz et al ${ }^{48}$ simultaneously recorded 306-channel MEG and 70-channel EEG in a 38-year-old woman with an $\mathrm{HH}$ who had suffered intractable complex partial seizures since the age of 2 years. They observed frequent and independent epileptic discharges from the left and right frontotemporal regions. Despite the lack of uniform methodology, MEG and magnetic source imaging may become a useful adjunct technique for the evaluation of patients with $\mathrm{HH}$ suffering from refractory seizures.

\section{Topological Classification}

There are 2 distinct anatomical subtypes of HHs (Fig. 


\section{Clinical, neuroimaging, and neurophysiological features of $\mathrm{HHs}$}

4). The first subtype, referred to as the intrahypothalamic or sessile $\mathrm{HH}$, consists of hamartomas that have either a partial or complete base of attachment within the third ventricle. ${ }^{62}$ These lesions can vary considerably in size but usually extend into the third ventricle and distort surrounding structures, including the fornix and mammillary bodies. ${ }^{45}$ There is a strong association between sessile HHs and neurological manifestations, including gelastic seizures. ${ }^{7,16,55,62,110}$ These lesions typically do not present with precocious puberty, although up to $40 \%$ of patients with sessile HHs may develop CPP at some point during the course of their disease. The second subtype is referred to as the parahypothalamic or pedunculated $\mathrm{HH}$. These lesions are attached only to the floor of the third ventricle or suspended from it by a peduncle. ${ }^{62}$ In contrast to sessile HHs, pedunculated lesions are typically not associated with a catastrophic childhood epilepsy syndrome or pervasive neurodevelopmental disorder. Rather, they are usually present with CPP in early childhood.

As mentioned earlier, the interference of HHs with inhibitory pathways onto GnRH neurons has been hypothesized as a possible mechanism for CPP. It is therefore conceivable that HHs are more likely to be associated with CPP if they are situated close to the GnRH nerve terminals in the median eminence, as in a parahypothalamic location. In addition, Inoue et al. ${ }^{54}$ showed that certain $\mathrm{HH}$ neurons contain GnRH-secreting vesicles. Resection of pedunculated lesions causing precocious puberty effectively reverses the hormonal irregularities. ${ }^{3,102}$ However, medical therapy in which long-acting GnRH analogs such as leuprolide acetate are used is now the primary treatment for most patients with $\mathrm{HH}$-related CPP. ${ }^{20,93} \mathrm{Al}$ though the majority of HHs can be easily classified as either sessile or pedunculated, some intermediary forms have been described. For example, a large sessile $\mathrm{HH}$ that has a broad attachment to the base of the hypothalamus and extends into the interpeduncular cistern may have features of both sessile and pedunculated HHs.

There is some evidence to support the notion that size, shape, and location of HHs affect the likelihood of clinical presentation. ${ }^{55}$ The HHs causing gelastic seizures tend to be larger than those associated with isolated CPP, and HH-related epilepsy occurs with medium to large sessile HHs that are widely attached to the mammillary body and tuber cinereum..$^{5,110}$ There may also be a doseresponse relationship between the size of the $\mathrm{HH}$ and the severity of the epileptic syndrome. ${ }^{104}$ However, size is probably not the only feature responsible for these clinical phenotypes. ${ }^{55}$ As noted earlier, Chan and colleagues ${ }^{27}$ found that HHs associated with CPP were larger and more likely to contact the infundibulum or tuber cinereum than hamartomas not associated with CPP. Figure 4 outlines the common topographical classifications of $\mathrm{HH}$ based on MRI findings described by various investigators.
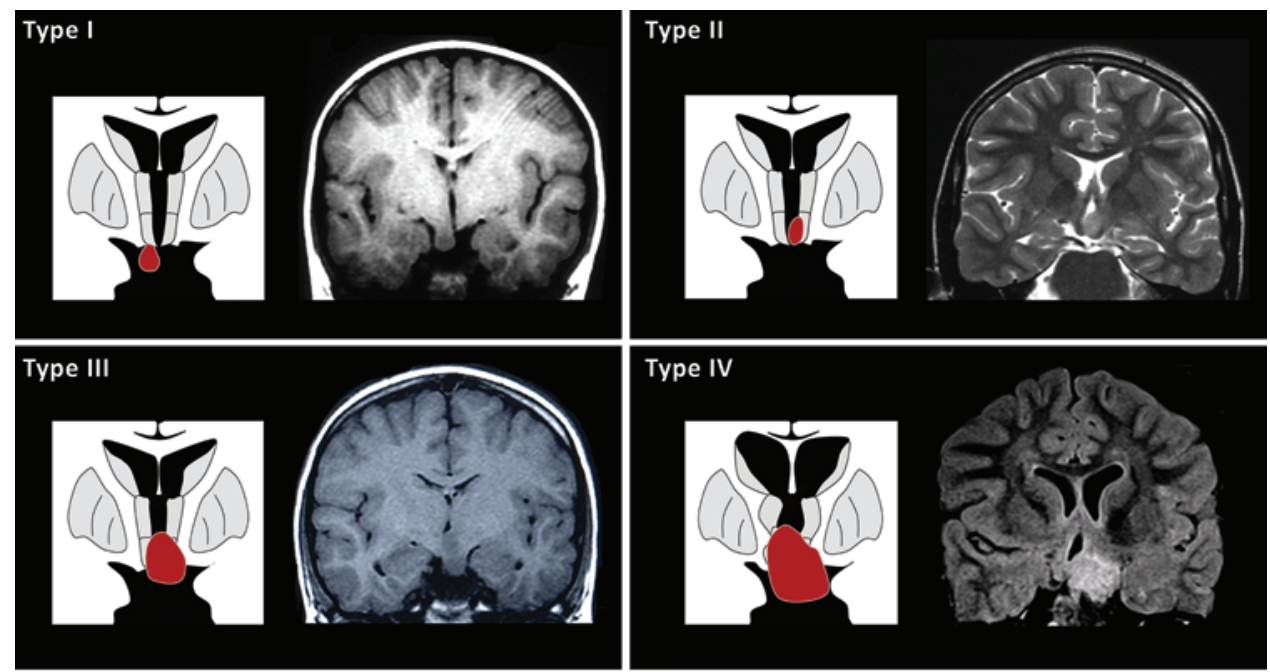

Author (Year)

Morphological Characteristics

Boyko et al. (1991)

Valdueza et al. (1994)

Arita et al. (1999)

Delalande and Fohlen (2003)

Régis et al. (2006)

\begin{tabular}{|c|c|c|c|c|c|c|c|}
\hline \multicolumn{2}{|c|}{ pedunculated } & \multicolumn{6}{|c|}{ sessile } \\
\hline $1 \mathrm{a}$ & $1 b$ & \multicolumn{3}{|c|}{$2 a$} & \multicolumn{3}{|c|}{$2 b$} \\
\hline \multicolumn{2}{|c|}{ parahypothalamic } & \multicolumn{6}{|c|}{ intrahypothalamic } \\
\hline \multicolumn{2}{|c|}{ I } & \multicolumn{2}{|c|}{ II } & \multicolumn{3}{|c|}{ III } & IV \\
\hline \multicolumn{2}{|c|}{ v } & 1 & II & III & IV & VI & Mixed \\
\hline
\end{tabular}

FIG. 4. Topological classification of HHs based on MRI findings. Delalande and Fohlen Type I HHs are small lesions with a horizontal plane of attachment to the tuber cinereum and may be lateralized to one side. Type II lesions are predominantly intraventricular and have a vertical plane of insertion. Type III lesions are a combination of Types I and II, with both a horizontal and a vertical insertion plane. Type IV lesions are generally very large tumors with broad attachment to the hypothalamus and mammillary bodies along with extension into the interpeduncular cistern. 


\section{Neuropathological, Neurobiological, and Neurophysiological Findings}

Discovering that HHs have intrinsic epileptogenicity provided a significant breakthrough in our knowledge of the pathobiological properties of these fascinating lesions. Hypothalamic hamartomas may predispose, through their mamillothalamic tract connections, a patient to generalized interictal spike and wave discharges as well as generalized seizures. ${ }^{73}$ Until recently, the histopathological features of HH remained poorly understood. Early analyses verified that the hamartomas were composed of disordered networks of neurons and supporting cells similar to other structural lesions linked with epilepsy such as focal cortical dysplasia. ${ }^{41}$ Immunohistochemical analysis of resected specimens showed that these neurons stained strongly for NeuN, a marker for mature neurons, and were surrounded by a fine fibrillary matrix positive for synaptophysin immunostaining (Fig. 5). Glial fibrillary acidic protein immunostaining showed scanty astrocytes and oligodendrocytes without neoplastic differentiation. ${ }^{110}$ Coons et al..$^{33}$ performed detailed histopathological analysis of 57 surgical HH cases. They noted that a constant feature of every resected $\mathrm{HH}$ specimen was the existence of neuronal clusters or nodules of variable size. These neuronal nodules were composed primarily of small bipolar neurons $(6-9 \mu \mathrm{m})$ intermingled with and encircled by large pyramidal neurons (18-22 $\mu \mathrm{m})$ in an astrocyte-rich neuropil. ${ }^{33,41}$ In a follow-up study, Wu et al. ${ }^{117}$ demonstrated that the majority of large $\mathrm{HH}$ neurons expressed the immature neuronal marker PSA-NCAM, whereas most small $\mathrm{HH}$ cells were predominantly immunoreactive to MAP-2, a mature neuronal marker. However, nodules of small neurons may not be a uniform feature of HHs, and only a small number of scattered neurons may be sufficient to cause seizures. ${ }^{114}$

Although it is possible that the epileptogenicity of cer- tain HHs may be due to intrinsic cellular dysplasia, ${ }^{57}$ the remarkable association between gelastic seizures and the intrahypothalamic position of the $\mathrm{HH}$ favors the premise that the epileptogenicity is more likely to be due to aberrant connectivity of these heterotopic structures. Fenoglio et al ${ }^{41}$ used slice preparations from resected HHs to evaluate how the cellular microarchitecture of the hamartoma might contribute to seizure generation. They evaluated the electrophysiological properties of both small and large neurons and examined their contribution to network activity; the authors noted spontaneous firing of action potentials in the small neurons. ${ }^{41,64}$ In addition to a continuous pacemaker-like firing pattern, these small neurons, which express $\mathrm{GABA}_{\mathrm{A}}$ receptors and are probably inhibitory interneurons, also exhibit irregular spiking and bursting firing patterns. ${ }^{118}$ In contrast, spontaneous activity was not detected in large $\mathrm{HH}$ neurons. ${ }^{41}$ Ultrastructural studies have also demonstrated that these 2 neuronal populations have distinct morphological and synaptic profiles. ${ }^{11}$ The investigators observed that $\mathrm{GABA}_{\mathrm{A}}$ receptors mediate neuronal excitation via activation of L-type calcium channels. 63,64 They hypothesized that the chronic epileptogenesis of $\mathrm{HH}$ tissue necessitates a complex network of organized and interconnected neuronal clusters to propagate and synchronize epileptic discharges ${ }^{41}$

In their follow-up studies using patch-clamp recordings of 93 dissociated $\mathrm{HH}$ neurons (76\% small interneurons and 24\% large neurons), the Barrow group noted that activation of $\mathrm{GABA}_{\mathrm{A}}$ receptors excited large but inhibited small HH neurons. ${ }^{117}$ Further work on $\mathrm{HH}$ slices with electrophysiological and calcium imaging techniques showed that bicarbonate $\left(\mathrm{HCO}_{3}{ }^{-}\right)$efflux through $\mathrm{GABA}_{\mathrm{A}}$ receptors on a subpopulation of large $\mathrm{HH}$ neurons may lead to activation of L-type calcium channels. ${ }^{63}$ Recently this group reported the presence of pathological high-frequency oscillations in $\mathrm{HH}$ tissue slices that were modulated by nifedipine, an L-type calcium channel blocker. ${ }^{100}$ Based on

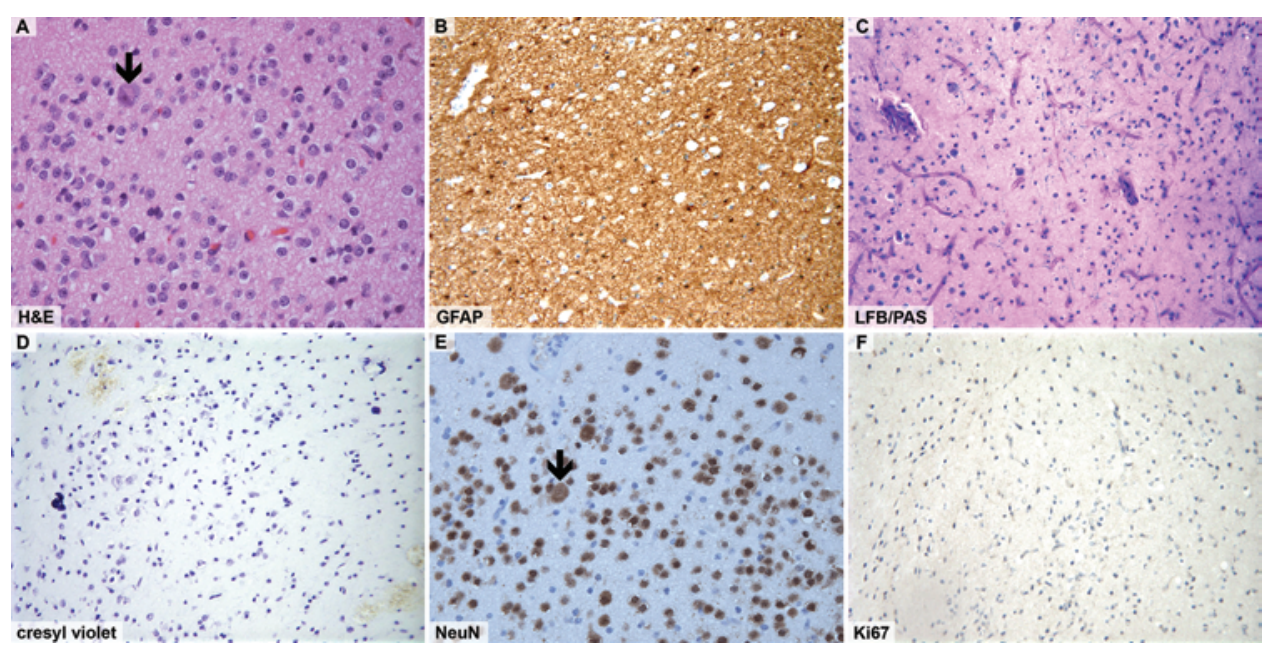

FIG. 5. Photomicrographs showing histopathological features of $\mathrm{HHs}$. On a routinely $\mathrm{H} \& \mathrm{E}$-stained section (A), there are both large neurons (ganglion cells; arrow) and smaller neuronal cells called neurocytes. They are surrounded by a neuropil-like matrix. Immunohistochemical investigation with glial fibrillary acidic protein stains the scattered glial cells without neoplastic differentiation (B). Luxol fast blue and periodic acid-Schiff stain for myelin and its breakdown products, and generally demonstrate only scattered myelinated axons (C). When stained with cresyl violet (D) or immunohistochemically with an antibody against the neuronal marker NeuN $(E)$, both large and small neurons are intensely positive. The arrow in panel $\mathrm{E}$ designates a ganglion cell. There is usually absent labeling for proliferation markers such as Ki-67 (F). Original magnification $\times 40(A$ and E) and $\times 20(B-D$ and F). 


\section{Clinical, neuroimaging, and neurophysiological features of HHs}

their collective data, they propose a model whereby clusters of small GABAergic interneurons display spontaneous rhythmic activity, which provides a tonic release of GABA onto the large $\mathrm{HH}$ projection neurons. This synchronized excitation of GABAergic innervation results in excitation of the large $\mathrm{HH}$ neurons, which in turn project to extrahypothalamic structures such as the hippocampus and thalamus; these structures are well known to play a central role in limbic epilepsies. These pioneering studies provide additional insight into possible mechanisms involved in the intrinsic epileptogenesis of $\mathrm{HHs}^{71}$

Interestingly, exposure of small $\mathrm{HH}$ neurons to ketone bodies decreased spontaneous firing in slice culture preparations. ${ }^{28}$ This may provide the pathophysiological basis of the modest benefit seen in a subset of patients with $\mathrm{HH}$ treated with a ketogenic diet. ${ }^{28}$ The main challenge will be to see how our improving knowledge of the underlying neurophysiological properties of HHs can be translated into enhanced medical and neurosurgical treatments. ${ }^{75}$

\section{Conclusions}

Hypothalamic hamartomas are rare nonneoplastic lesions composed of a complex network of neurons, glia, and myelinated fibers. Epileptogenic HHs are usually sessile and closely associated with the mammillary bodies. Patients typically present with gelastic seizures in early childhood and can progress to a devastating clinical syndrome, which by a process of secondary epileptogenesis may include various types of refractory seizures with secondary generalization, progressive cognitive deterioration, and worsening behavior and psychiatric function. Contrary to earlier studies, which ascribed seizure onset to neocortical regions, the hamartoma itself has now been decisively recognized as the source of intrinsic epileptogenesis leading to the stereotyped, emotionless ictal laughter characteristic of gelastic seizures. In some patients, HHs may also be involved in secondary epileptogenesis, with subsequent development of multiple seizure types of cortical onset. Antiepileptic drugs are typically ineffective in controlling the HH-related seizures. Despite significant risks associated with surgical treatment of $\mathrm{HHs}$, it appears that an aggressive approach involving various neurosurgical options may lead to a more favorable outcome. The various neurosurgical strategies used to treat $\mathrm{HHs}$ and their outcomes are addressed in the second article of this 2-part review.

\section{Disclosure}

The authors report no conflict of interest concerning the materials or methods used in this study or the findings specified in this paper.

Author contributions to the study and manuscript preparation include the following. Conception and design: S Mittal. Acquisition of data: all authors. Analysis and interpretation of data: S Mittal. Drafting the article: S Mittal, M Mittal. Critically revising the article: all authors. Reviewed submitted version of manuscript: all authors. Approved the final version of the manuscript on behalf of all authors: S Mittal. Administrative/technical/material support: S Mittal. Study supervision: S Mittal.

\section{Acknowledgments}

The authors thank Brandon J. Parker, M.P.A., and Neena Marupudi, M.D., for editorial assistance.

\section{References}

1. Acharya SV, Gopal RA, Menon PS, Bandgar TR, Shah NS: A rare case of central precocious puberty due to hypothalamic hamartoma diagnosed in utero. Endocr Pract 16:237-240, 2010

2. Al-Hail HJ, Sokrab TE, Al-Moslamani NJ, Miyares FR: Hypothalamic hamartoma presenting with gelastic seizures, generalized convulsions, and ictal psychosis. Neurosciences (Riyadh) 15:43-45, 2010

3. Albright AL, Lee PA: Surgery for hypothalamic hamartomas. J Neurosurg 88:353, 1998 (Letter)

4. Ali S, Moriarty J, Mullatti N, David A: Psychiatric comorbidity in adult patients with hypothalamic hamartoma. Epilepsy Behav 9:111-118, 2006

5. Amstutz DR, Coons SW, Kerrigan JF, Rekate HL, Heiserman JE: Hypothalamic hamartomas: Correlation of MR imaging and spectroscopic findings with tumor glial content. AJNR Am J Neuroradiol 27:794-798, 2006

6. Andermann F, Arzimanoglou A, Berkovic SF: Hypothalamic hamartoma and epilepsy: the pathway of discovery. Epileptic Disord 5:173-175, 2003

7. Arita K, Ikawa F, Kurisu K, Sumida M, Harada K, Uozumi T, et al: The relationship between magnetic resonance imaging findings and clinical manifestations of hypothalamic hamartoma. J Neurosurg 91:212-220, 1999

8. Arroyo S, Lesser RP, Gordon B, Uematsu S, Hart J, Schwerdt $\mathrm{P}$, et al: Mirth, laughter and gelastic seizures. Brain 116:757780, 1993

9. Arroyo S, Santamaría J, Sanmartí F, Lomena F, Catafau A, Casamitjana R, et al: Ictal laughter associated with paroxysmal hypothalamopituitary dysfunction. Epilepsia 38:114117,1997

10. Arzimanoglou AA, Hirsch E, Aicardi J: Hypothalamic hamartoma and epilepsy in children: illustrative cases of possible evolutions. Epileptic Disord 5:187-199, 2003

11. Beggs J, Nakada S, Fenoglio K, Wu J, Coons S, Kerrigan JF: Hypothalamic hamartomas associated with epilepsy: ultrastructural features. J Neuropathol Exp Neurol 67:657-668, 2008

12. Berberoğlu M: Precocious puberty and normal variant puberty: definition, etiology, diagnosis and current management. J Clin Res Pediatr Endocrinol 1:164-174, 2009

13. Berkovic SF, Andermann F, Melanson D, Ethier RE, Feindel W, Gloor P: Hypothalamic hamartomas and ictal laughter: evolution of a characteristic epileptic syndrome and diagnostic value of magnetic resonance imaging. Ann Neurol 23: 429-439, 1988

14. Berkovic SF, Kuzniecky RI, Andermann F: Human epileptogenesis and hypothalamic hamartomas: new lessons from an experiment of nature. Epilepsia 38:1-3, 1997

15. Bertrand N, Dahmane N: Sonic hedgehog signaling in forebrain development and its interactions with pathways that modify its effects. Trends Cell Biol 16:597-605, 2006

16. Boyko OB, Curnes JT, Oakes WJ, Burger PC: Hamartomas of the tuber cinereum: CT, MR, and pathologic findings. AJNR Am J Neuroradiol 12:309-314, 1991

17. Brandberg G, Raininko R, Eeg-Olofsson O: Hypothalamic hamartoma with gelastic seizures in Swedish children and adolescents. Eur J Paediatr Neurol 8:35-44, 2004

18. Bunyaratavej K, Locharernkul C, Tepmongkol S, Lerdlum S, Shuangshoti S, Khaoroptham S: Successful resection of Hypothalamic Hamartoma with intractable gelastic seizures-by transcallosal subchoroidal approach. J Med Assoc Thai 89: 1269-1276, 2006

19. Burghardt T, Basha MM, Fuerst D, Mittal S: Crying with sorrow evoked by electrocortical stimulation. Epileptic Disord [epub ahead of print], 2013

20. Carel JC, Eugster EA, Rogol A, Ghizzoni L, Palmert MR, 
Antoniazzi F, et al: Consensus statement on the use of gonadotropin-releasing hormone analogs in children. Pediatrics 123:e752-e762, 2009

21. Cascino GD, Andermann F, Berkovic SF, Kuzniecky RI, Sharbrough FW, Keene DL, et al: Gelastic seizures and hypothalamic hamartomas: evaluation of patients undergoing chronic intracranial EEG monitoring and outcome of surgical treatment. Neurology 43:747-750, 1993

22. Cassio A, Cacciari E, Zucchini S, Balsamo A, Diegoli M, Orsini F: Central precocious puberty: clinical and imaging aspects. J Pediatr Endocrinol Metab 13 (Suppl 1):703-708, 2000

23. Castaño De La Mota C, Martín Del Valle F, Pérez Villena A, Calleja Gero ML, Losada Del Pozo R, Ruiz-Falcó Rojas ML: [Hypothalamic hamartoma in paediatric patients: clinical characteristics, outcomes and review of the literature.] Neurologia 27:268-276, 2012 (Span)

24. Castro LH, Ferreira LK, Teles LR, Jorge CL, Arantes PR, Ono $\mathrm{CR}$, et al: Epilepsy syndromes associated with hypothalamic hamartomas. Seizure 16:50-58, 2007

25. Celedin S, Kau T, Gasser J, Kraschl R, Sinzig M: Fetal MRI of a hypothalamic hamartoma in Pallister-Hall syndrome. Pediatr Neurol 42:59-60, 2010

26. Cercy SP, Kuluva JE: Gelastic epilepsy and dysprosodia in a case of late-onset right frontal seizures. Epilepsy Behav 16: 360-365, 2009

27. Chan YM, Fenoglio-Simeone KA, Paraschos S, Muhammad L, Troester MM, Ng YT, et al: Central precocious puberty due to hypothalamic hamartomas correlates with anatomic features but not with expression of GnRH, TGFalpha, or KISS1. Horm Res Paediatr 73:312-319, 2010

28. Chapman KE, Kim DY, Rho JM, Ng YT, Kerrigan JF: Ketogenic diet in the treatment of seizures associated with hypothalamic hamartomas. Epilepsy Res 94:218-221, 2011

29. Chernov MF, Kawamata T, Amano K, Ono Y, Suzuki T, Nakamura R, et al: Possible role of single-voxel (1)H-MRS in differential diagnosis of suprasellar tumors. J Neurooncol 91: 191-198, 2009

30. Cheung CS, Parrent AG, Burneo JG: Gelastic seizures: not always hypothalamic hamartoma. Epileptic Disord 9:453-458, 2007

31. Choi JU, Yang KH, Kim TG, Chang JH, Chang JW, Lee BI, et al: Endoscopic disconnection for hypothalamic hamartoma with intractable seizure. Report of four cases. J Neurosurg 100 (5 Suppl Pediatrics):506-511, 2004

32. Cook T, Joshi C: Gelastic seizures in tuberous sclerosis complex: case report and literature review. J Child Neurol 26:8386,2011

33. Coons SW, Rekate HL, Prenger EC, Wang N, Drees C, Ng YT, et al: The histopathology of hypothalamic hamartomas: study of 57 cases. J Neuropathol Exp Neurol 66:131-141, 2007

34. Craig DW, Itty A, Panganiban C, Szelinger S, Kruer MC, Sekar A, et al: Identification of somatic chromosomal abnormalities in hypothalamic hamartoma tissue at the GLI3 locus. Am J Hum Genet 82:366-374, 2008

35. Daly DD, Mulder DW: Gelastic epilepsy. Neurology 7:189192, 1957

36. Daniel PM: Anatomy of the hypothalamus and pituitary gland. J Clin Pathol Suppl (Assoc Clin Pathol) 7:1-7, 1976

37. Delalande O, Fohlen M: Disconnecting surgical treatment of hypothalamic hamartoma in children and adults with refractory epilepsy and proposal of a new classification. Neurol Med Chir (Tokyo) 43:61-68, 2003

38. DiFazio MP, Davis RG: Utility of early single photon emission computed tomography (SPECT) in neonatal gelastic epilepsy associated with hypothalamic hamartoma. J Child Neurol 15: 414-417, 2000

39. Dorfer C, Kasprian G, Mühlebner A, Czech T: Giant solidcystic hypothalamic hamartoma. Case report. Neurosurg Focus 30(2):E7, 2011
40. Dunoyer C, Ragheb J, Resnick T, Alvarez L, Jayakar P, Altman N, et al: The use of stereotactic radiosurgery to treat intractable childhood partial epilepsy. Epilepsia 43:292-300, 2002

41. Fenoglio KA, Wu J, Kim DY, Simeone TA, Coons SW, Rekate $\mathrm{H}$, et al: Hypothalamic hamartoma: basic mechanisms of intrinsic epileptogenesis. Semin Pediatr Neurol 14:51-59, 2007

42. Fohlen M, Lellouch A, Delalande O: Hypothalamic hamartoma with refractory epilepsy: surgical procedures and results in 18 patients. Epileptic Disord 5:267-273, 2003

43. Frattali CM, Liow K, Craig GH, Korenman LM, Makhlouf F, Sato $S$, et al: Cognitive deficits in children with gelastic seizures and hypothalamic hamartoma. Neurology 57:43-46, 2001

44. Freeman JL: The anatomy and embryology of the hypothalamus in relation to hypothalamic hamartomas. Epileptic Disord 5:177-186, 2003

45. Freeman JL, Coleman LT, Wellard RM, Kean MJ, Rosenfeld JV, Jackson GD, et al: MR imaging and spectroscopic study of epileptogenic hypothalamic hamartomas: analysis of 72 cases. AJNR Am J Neuroradiol 25:450-462, 2004

46. Funke M, Constantino T, Van Orman C, Rodin E: Magnetoencephalography and magnetic source imaging in epilepsy. Clin EEG Neurosci 40:271-280, 2009

47. Gascon GG, Lombroso CT: Epileptic (gelastic) laughter. Epilepsia 12:63-76, 1971

48. Goldenholz DM, Ahlfors SP, Hämäläinen MS, Sharon D, Ishitobi M, Vaina LM, et al: Mapping the signal-to-noise-ratios of cortical sources in magnetoencephalography and electroencephalography. Hum Brain Mapp 30:1077-1086, 2009

49. Hahn FJ, Leibrock LG, Huseman CA, Makos MM: The MR appearance of hypothalamic hamartoma. Neuroradiology 30: 65-68, 1988

50. Hall JG, Pallister PD, Clarren SK, Beckwith JB, Wiglesworth FW, Fraser FC, et al: Congenital hypothalamic hamartoblastoma, hypopituitarism, imperforate anus and postaxial polydactyly - a new syndrome? Part I: clinical, causal, and pathogenetic considerations. Am J Med Genet 7:47-74, 1980

51. Harvey AS, Freeman JL: Epilepsy in hypothalamic hamartoma: clinical and EEG features. Semin Pediatr Neurol 14: 60-64, 2007

52. Hou XY, Gao PY: [Clinical and imaging features of hypothalamic hamartoma in children.] Zhongguo Dang Dai Er Ke Za Zhi 11:364-366, 2009 (Chinese)

53. Hu WH, Zhang K, Shao XQ, Li D, Bai Q, Qiao H, et al: Surgical outcome of gelastic epilepsy of frontal lobe origin: a case report. Seizure 20:352-356, 2011

54. Inoue HK, Kanazawa H, Kohga H, Zama A, Ono N, Nakamura M, et al: Hypothalamic hamartoma: anatomic, immunohistochemical and ultrastructural features. Noshuyo Byori 12:45-51, 1995

55. Jung H, Neumaier Probst E, Hauffa BP, Partsch CJ, Dammann $\mathrm{O}$ : Association of morphological characteristics with precocious puberty and/or gelastic seizures in hypothalamic hamartoma. J Clin Endocrinol Metab 88:4590-4595, 2003

56. Jung H, Parent AS, Ojeda SR: Hypothalamic hamartoma: a paradigm/model for studying the onset of puberty. Endocr Dev 8:81-93, 2005

57. Kahane P, Di Leo M, Hoffmann D, Munari C: Ictal bradycardia in a patient with a hypothalamic hamartoma: a stereoEEG study. Epilepsia 40:522-527, 1999

58. Kahane P, Ryvlin P, Hoffmann D, Minotti L, Benabid AL: From hypothalamic hamartoma to cortex: what can be learnt from depth recordings and stimulation? Epileptic Disord 5: 205-217, 2003

59. Kameyama S, Masuda H, Murakami H: Ictogenesis and symptomatogenesis of gelastic seizures in hypothalamic hamartomas: an ictal SPECT study. Epilepsia 51:2270-2279, 2010

60. Kang S, Graham JM Jr, Olney AH, Biesecker LG: GLI3 frameshift mutations cause autosomal dominant Pallister-Hall syndrome. Nat Genet 15:266-268, 1997 


\section{Clinical, neuroimaging, and neurophysiological features of $\mathrm{HHs}$}

61. Kerrigan JF, Kruer MC, Corneveaux J, Panganiban CB, Itty A, Reiman D, et al: Chromosomal abnormality at 6p25.1-25.3 identifies a susceptibility locus for hypothalamic hamartoma associated with epilepsy. Epilepsy Res 75:70-73, 2007

62. Kerrigan JF, Ng YT, Chung S, Rekate HL: The hypothalamic hamartoma: a model of subcortical epileptogenesis and encephalopathy. Semin Pediatr Neurol 12:119-131, 2005

63. Kim DY, Fenoglio KA, Kerrigan JF, Rho JM: Bicarbonate contributes to GABAA receptor-mediated neuronal excitation in surgically resected human hypothalamic hamartomas. Epilepsy Res 83:89-93, 2009

64. Kim Y, Fenoglio KA, Simeone TA, Coons SW, Wu J, Chang Y, et al: GABAA receptor-mediated activation of L-type calcium channels induces neuronal excitation in surgically resected human hypothalamic hamartomas. Epilepsia 49:861871,2008

65. Kokkinos V, Zountsas B, Kontogiannis K, Garganis K: Epileptogenic networks in two patients with hypothalamic hamartoma. Brain Topogr 25:327-331, 2012

66. Kovac S, Deppe M, Mohammadi S, Schiffbauer H, Schwindt W, Möddel G, et al: Gelastic seizures: a case of lateral frontal lobe epilepsy and review of the literature. Epilepsy Behav 15:249-253, 2009

67. Kuzniecky R, Guthrie B, Mountz J, Bebin M, Faught E, Gilliam F, et al: Intrinsic epileptogenesis of hypothalamic hamartomas in gelastic epilepsy. Ann Neurol 42:60-67, 1997

68. Lai K, Kaspar BK, Gage FH, Schaffer DV: Sonic hedgehog regulates adult neural progenitor proliferation in vitro and in vivo. Nat Neurosci 6:21-27, 2003

69. Leal AJ, Monteiro JP, Secca MF, Jordão C: Functional brain mapping of ictal activity in gelastic epilepsy associated with hypothalamic hamartoma: a case report. Epilepsia 50:16241631,2009

70. Leal AJ, Moreira A, Robalo C, Ribeiro C: Different electroclinical manifestations of the epilepsy associated with hamartomas connecting to the middle or posterior hypothalamus. Epilepsia 44:1191-1195, 2003

71. Lekovic GP, Kerrigan JF, Wait S, Rekate HL, Steinmetz PN: In situ single-unit recording of hypothalamic hamartomas under endoscopic direct visualization. Neurosurgery 65:E1195E1196, 2009

72. Lona Soto A, Takahashi M, Yamashita Y, Sakamoto Y, Shinzato J, Yoshizumi K: MRI findings of hypothalamic hamartoma: report of five cases and review of the literature. Comput Med Imaging Graph 15:415-421, 1991

73. Maixner W: Hypothalamic hamartomas-clinical, neuropathological and surgical aspects. Childs Nerv Syst 22:867873,2006

74. Martin DD, Seeger U, Ranke MB, Grodd W: MR imaging and spectroscopy of a tuber cinereum hamartoma in a patient with growth hormone deficiency and hypogonadotropic hypogonadism. AJNR Am J Neuroradiol 24:1177-1180, 2003

75. Mittal S, Mittal M, Montes JL, Farmer JP, Andermann F: Hypothalamic hamartomas. Part 2. Surgical considerations and outcome. Neurosurg Focus 34(6):E7, 2013

76. Mori K, Handa H, Takeuchi J, Hanakita J, Nakano Y: Hypothalamic hamartoma. J Comput Assist Tomogr 5:519-521, 1981

77. Mullatti N: Hypothalamic hamartoma in adults. Epileptic Disord 5:201-204, 2003

78. Mullatti N, Selway R, Nashef L, Elwes R, Honavar M, Chandler C, et al: The clinical spectrum of epilepsy in children and adults with hypothalamic hamartoma. Epilepsia 44:13101319,2003

79. Munari C, Kahane P, Francione S, Hoffmann D, Tassi L, Cusmai R, et al: Role of the hypothalamic hamartoma in the genesis of gelastic fits (a video-stereo-EEG study). Electroencephalogr Clin Neurophysiol 95:154-160, 1995

80. Oehl B, Biethahn S, Schulze-Bonhage A: Mirthful gelastic seizures with ictal involvement of temporobasal regions. Epileptic Disord 11:82-86, 2009

81. Oehl B, Brandt A, Fauser S, Bast T, Trippel M, Schulze-Bonhage A: Semiologic aspects of epileptic seizures in 31 patients with hypothalamic hamartoma. Epilepsia 51:2116-2123, 2010

82. Palmini A, Chandler C, Andermann F, Costa Da Costa J, Paglioli-Neto E, Polkey C, et al: Resection of the lesion in patients with hypothalamic hamartomas and catastrophic epilepsy. Neurology 58:1338-1347, 2002

83. Palmini A, Van Paesschen W, Dupont P, Van Laere K, Van Driel G: Status gelasticus after temporal lobectomy: ictal FDG-PET findings and the question of dual pathology involving hypothalamic hamartomas. Epilepsia 46:1313-1316, 2005

84. Pang D, Rosenbaum AE, Wilberger JE Jr, Gutai JP: Metrizamide computed tomographic cisternography for the diagnosis of occult lesions of the hypothalamic-hypophyseal axis in children. Neurosurgery 8:531-541, 1981

85. Parent AS, Matagne V, Westphal M, Heger S, Ojeda S, Jung $\mathrm{H}$ : Gene expression profiling of hypothalamic hamartomas: a search for genes associated with central precocious puberty. Horm Res 69:114-123, 2008

86. Park C, Wethe JV, Kerrigan JF: Decreased quality of life in children with hypothalamic hamartoma and treatment-resistant epilepsy. J Child Neurol 28:50-55, 2013

87. Pascual-Castroviejo I, Moneo JH, Viaño J, García-Segura JM, Herguido MJ, Pascual Pascual SI: [Hypothalamic hamartomas: control of seizures after partial removal in one case.] Rev Neurol 31:119-122, 2000 (Span)

88. Pleasure SJ, Guerrini R: Hypothalamic hamartomas and hedgehogs: not a laughing matter. Neurology 70:588-589, 2008

89. Poretti A, Brehmer U, Scheer I, Bernet V, Boltshauser E: Prenatal and neonatal MR imaging findings in oral-facial-digital syndrome type VI. AJNR Am J Neuroradiol 29:1090-1091, 2008

90. Prigatano GP, Wethe JV, Gray JA, Wang N, Chung S, Ng YT, et al: Intellectual functioning in presurgical patients with hypothalamic hamartoma and refractory epilepsy. Epilepsy Behav 13:149-155, 2008

91. Quiske A, Frings L, Wagner K, Unterrainer J, Schulze-Bonhage A: Cognitive functions in juvenile and adult patients with gelastic epilepsy due to hypothalamic hamartoma. Epilepsia 47:153-158, 2006

92. Régis J, Scavarda D, Tamura M, Nagayi M, Villeneuve N, Bartolomei F, et al: Epilepsy related to hypothalamic hamartomas: surgical management with special reference to gamma knife surgery. Childs Nerv Syst 22:881-895, 2006

93. Rousso IH, Kourti M, Papandreou D, Tragiannidis A, Athanasiadou F: Central precocious puberty due to hypothalamic hamartoma in a 7-month-old infant girl. Eur J Pediatr 167:583-585, 2008

94. Ryvlin P, Ravier C, Bouvard S, Mauguire F, Le Bars D, Arzimanoglou A, et al: Positron emission tomography in epileptogenic hypothalamic hamartomas. Epileptic Disord 5:219227,2003

95. Savard G, Bhanji NH, Dubeau F, Andermann F, Sadikot A: Psychiatric aspects of patients with hypothalamic hamartoma and epilepsy. Epileptic Disord 5:229-234, 2003

96. Seith A, Kandpal H, Khadgawat R: Hypothalamic hamartoma: MR imaging and MR spectroscopic features. Singapore Med J 49:366-367, 2008

97. Shahar E, Goldsher D, Genizi J, Ravid S, Keidar Z: Intractable gelastic seizures during infancy: ictal positron emission tomography (PET) demonstrating epileptiform activity within the hypothalamic hamartoma. J Child Neurol 23:235-239, 2008

98. Shahar E, Kramer U, Mahajnah M, Lerman-Sagie T, Goez R, Gross V, et al: Pediatric-onset gelastic seizures: clinical data and outcome. Pediatr Neurol 37:29-34, 2007 


\section{S. Mittal et al.}

99. Shumake J, Edwards E, Gonzalez-Lima F: Hypermetabolism of paraventricular hypothalamus in the congenitally helpless rat. Neurosci Lett 311:45-48, 2001

100. Simeone KA, Sabesan S, Kim Y, Kerrigan JF, Rho JM, Simeone TA: L-Type calcium channel blockade reduces network activity in human epileptic hypothalamic hamartoma tissue. Epilepsia 52:531-540, 2011

101. Stefan H: Magnetic source imaging. Rev Neurol (Paris) 165: 742-745, 2009

102. Stewart L, Steinbok P, Daaboul J: Role of surgical resection in the treatment of hypothalamic hamartomas causing precocious puberty. Report of six cases. J Neurosurg 88: 340-345, 1998

103. Striano S, Striano P, Coppola A, Romanelli P: The syndrome gelastic seizures-hypothalamic hamartoma: severe, potentially reversible encephalopathy. Epilepsia 50 (Suppl 5): 62-65, 2009

104. Sturm JW, Andermann F, Berkovic SF: "Pressure to laugh": an unusual epileptic symptom associated with small hypothalamic hamartomas. Neurology 54:971-973, 2000

105. Tasch E, Cendes F, Li LM, Dubeau F, Montes J, Rosenblatt B, et al: Hypothalamic hamartomas and gelastic epilepsy: a spectroscopic study. Neurology 51:1046-1050, 1998

106. Tassinari CA, Riguzzi P, Rizzi R, Passarelli D, Volpi L: Gelastic seizures, in Tuxhorn I, Holthausen H, Boenighk K (eds): Pediatric Epilepsy Syndromes and Their Surgical Treatment. London: John Libbey, 1997, pp 429-446

107. Troester M, Haine-Schlagel R, Ng YT, Chapman K, Chung $\mathrm{S}$, Drees $\mathrm{C}$, et al: EEG and video-EEG seizure monitoring has limited utility in patients with hypothalamic hamartoma and epilepsy. Epilepsia 52:1137-1143, 2011

108. Trousseau A: Clinique Médicale de l'Hôtel-Dieu de Paris, ed 4. Paris: J-B Baillière et fils, 1873

109. Umeoka S, Baba K, Mihara T: Symptomatic laughter in a patient with orbitofrontal seizure: A surgical case with intracranial electroencephalographic study: case report. Neurosurgery 63:E1205-E1206, 2008

110. Valdueza JM,Cristante L, Dammann O, Bentele K, Vortmeyer A, Saeger W, et al: Hypothalamic hamartomas: with special reference to gelastic epilepsy and surgery. Neurosurgery 34: 949-958, 1994

111. Veendrick-Meekes MJ, Verhoeven WM, van Erp MG, van Blarikom W, Tuinier S: Neuropsychiatric aspects of patients with hypothalamic hamartomas. Epilepsy Behav 11:218-221, 2007
112. Wakai S, Nikaido K, Nihira H, Kawamoto Y, Hayasaka $\mathrm{H}$ : Gelastic seizure with hypothalamic hamartoma: proton magnetic resonance spectrometry and ictal electroencephalographic findings in a 4-year-old girl. J Child Neurol 17: 44-46, 2002

113. Wakamoto H, Sumi A, Motoki T, Ohmori H: Positron emission tomography with glucose hypermetabolism of a hypothalamic hamartoma in infantile spasms associated with Pallister-Hall syndrome. Brain Dev 32:677-680, 2010

114. Waldau B, McLendon RE, Fuchs HE, George TM, Grant GA: Few isolated neurons in hypothalamic hamartomas may cause gelastic seizures. Pediatr Neurosurg 45:225-229, 2009

115. Wallace RH, Freeman JL, Shouri MR, Izzillo PA, Rosenfeld JV, Mulley JC, et al: Somatic mutations in GLI3 can cause hypothalamic hamartoma and gelastic seizures. Neurology 70:653-655, 2008

116. Weissenberger AA, Dell ML, Liow K, Theodore W, Frattali CM, Hernandez D, et al: Aggression and psychiatric comorbidity in children with hypothalamic hamartomas and their unaffected siblings. J Am Acad Child Adolesc Psychiatry 40:696-703, 2001

117. Wu J, DeChon J, Xue F, Li G, Ellsworth K, Gao M, et al: $\mathrm{GABA}(\mathrm{A})$ receptor-mediated excitation in dissociated neurons from human hypothalamic hamartomas. Exp Neurol 213: 397-404, 2008

118. Wu J, Xu L, Kim DY, Rho JM, St John PA, Lue LF, et al: Electrophysiological properties of human hypothalamic hamartomas. Ann Neurol 58:371-382, 2005

119. Yamaguchi S, Suzuki SO, Matsuo Y, Uesaka T, Matsukado $\mathrm{K}$, Masui K, et al: Large hypothalamic hamartoma with calcification and cystic components in an adult-case report. Neurol Med Chir (Tokyo) 50:495-498, 2010

Manuscript submitted February 12, 2013.

Accepted March 13, 2013.

Please include this information when citing this paper: DOI: 10.3171/2013.3.FOCUS1355.

Address correspondence to: Sandeep Mittal, M.D., F.R.C.S.C., Department of Neurosurgery, Wayne State University, 4160 John R Street, Suite 930, Detroit, Michigan 48201. email: smittal@med. wayne.edu. 